\title{
Post-Contrast Acute Kidney Injury and Intravenous Prophylactic Hydration: An Update
}

\section{Kontrastmittelinduzierte Nephropathie: Aktueller Stand präventiver Maßnahmen}

Authors

Estelle Claire Nijssen ${ }^{1}$, Roger Rennenberg ${ }^{2}$, Patty Nelemans ${ }^{3}$, Vincent van Ommen ${ }^{4}$, Joachim E. Wildberger ${ }^{1}$

Affiliations

1 Radiology \& Nuclear Medicine, Maastricht University Medical Centre+, Maastricht, Netherlands

2 Internal Medicine, Maastricht University Medical Centre+, Maastricht, Netherlands

3 Epidemiology, Maastricht University, Maastricht, Netherlands

4 Cardiology, Maastricht University Medical Centre+, Maastricht, Netherlands

Key words

contrast agents, acute kidney injury, preventive measures, clinical practice guideline

received 10.03 .2020

accepted 20.08.2020

published online 16.12 .2020

Bibliography

Fortschr Röntgenstr 2021; 193: 151-159

DOI 10.1055/a-1248-9178

ISSN 1438-9029

(C) 2020. Thieme. All rights reserved.

Georg Thieme Verlag KG, Rüdigerstraße 14,

70469 Stuttgart, Germany

Correspondence

Dr. Estelle Claire Nijssen

Radiology \& Nuclear Medicine, Maastricht University Medical Centre+, PO Box 5800, 6202 AZ Maastricht, Netherlands

Tel.: ++ 31/43/3872649

estelle.nijssen@mumc.nl

\section{ZUSAMMENFASSUNG}

Hintergrund Die intravaskuläre Applikation jodhaltiger Kontrastmittel kann, trotz kontinuierlicher Verbesserung ihrer pharmakologischen Eigenschaften, systemische bzw. hämodynamische Nebenwirkungen haben. Insbesondere Patienten mit eingeschränkter Nierenfunktion sind gefährdet. Ein akutes Nierenversagen im Nachgang einer intravaskulären Kontrastmittelgabe hat für betroffene Patienten im Langzeitverlauf ein erhöhtes Dialyse- und Mortalitätsrisiko. Weder ist der zugrunde liegende Pathomechanismus vollständig geklärt, noch ist die wirkliche Inzidenz eines akuten Nierenversa- gens im Rahmen einer kontrastmittelinduzierten Nephropathie bekannt. Diese Unsicherheiten spiegeln sich in vielen weiteren Aspekten wider: so fehlt beispielsweise eine allgemein verbindliche Definition und ist der Umgang in der klinischen Praxis uneinheitlich.

Methode Klinische Leitlinien zur Prävention einer kontrastmittelinduzierten Nierenschädigung empfehlen klassischerweise eine prophylaktische intravenöse Hydrierung von Hochrisikopatienten. In der vorliegenden Übersicht werden die gültigen Empfehlungen zur intravenösen Prophylaxe in diesem Kontext zusammengefasst und ein 2-stufiger Praxisleitfaden auf Basis der letzten Leitlinienempfehlungen vorgestellt. Ergebnisse Jüngere Forschungsergebnisse haben zu einer weitreichenden Anpassung der klinischen Leitlinienempfehlungen geführt: 90 \% der bis dato als Hochrisiko für kontrastmittelinduzierte Nephropathie eingestuften Patienten gehören nicht länger in diese Risikokategorie, eine diesbezügliche Prophylaxe vor Kontrastmittelgabe wird nicht mehr empfohlen. Für eine kleine Patientengruppe kann diese Prophylaxe sehr wohl hilfreich sein, unter sorgfältiger Abwägung im Rahmen einer Nutzen-Risiko-Analyse. Dies betrifft insbesondere Patienten mit chronischer Niereninsuffizienz im Stadium CKD 4 und 5.

Schlussfolgerung Intravenöse Hydratation kann einen positiven Effekt haben für Hochrisikopatienten gemäß der „neuen” Definition; eine Risikoabwägung bleibt notwendig. Ein 2-stufiger Screening-Ansatz bietet Hilfestellung für die praktische Implementierung in der Klinik.

\section{Kernaussagen:}

- Prophylaktische Prähydrierung ist ein wesentlicher Baustein, um eine kontrastmittelinduzierte Nephropathie zu vermeiden.

- Jüngere Publikationen haben zu einer Anpassung der gegenwärtigen Leitlinienempfehlungen beigetragen.

- Intravenöse Hydratation kann einen positiven Effekt haben für Hochrisikopatienten gemäß der „neuen” Definition; eine Risikoabwägung bleibt notwendig.

- Ein 2-stufiger Screening-Ansatz bietet Hilfestellung für die praktische Implementierung in der Klinik.

\section{ABSTRACT}

Background Despite tremendous improvement in molecular properties over the last century, intravascular injection of 
iodinated contrast material may still have systemic and hemodynamic consequences. Patients with pre-existing renal insufficiency may be at risk for acute kidney injury, which may be associated with an increased risk of the need for dialysis and mortality in the long term. Many questions as to the physiological pathways, optimal definition, and incidence of contrast-induced acute kidney injury remain open. These uncertainties are reflected in the changing landscape of this field in terms of nomenclature, research, and clinical practice.

Methods Clinical practice guidelines for the prevention of post-contrast acute kidney injury all recommend giving prophylaxis in the form of intravenous hydration to high-risk patients. Solid evidence for this strategy is lacking. This article gives an overview of the changing landscape of post-contrast acute kidney injury and prophylactic intravenous hydration, with the aim of supporting informed decision-making in clinical practice.

Results Recent data have caused a shift in guideline recommendations: $90 \%$ of patients formerly considered high-risk for contrast-induced acute kidney injury no longer qualify for prophylaxis. The remaining high-risk patients, with severe chronic kidney disease, represent a vulnerable population for whom intravenous hydration may provide some benefits but also carries risk.

Conclusion Intravenous hydration may benefit 'new' highrisk patients. However, it also confers risk. A dual approach to screening patients will help avoid this risk in clinical practice.

\section{Key Points:}

- Intravenous hydration is the cornerstone for preventing contrast-induced acute kidney injury

- Solid evidence is lacking; recent data caused a shift in guideline recommendations

- Intravenous hydration may benefit 'new' high-risk patients with severe chronic kidney disease; however, it also confers risk

- A dual approach to screening patients will help avoid this risk in clinical practice

\section{Citation Format}

- Nijssen E, Rennenberg R, Nelemans P et al. Post-Contrast Acute Kidney Injury and Intravenous Prophylactic Hydration: An Update. Fortschr Röntgenstr 2021; 193: 151-159

\section{Background}

Administrating contrast agents for medical purposes has a long history. It dates back to the early $1920 \mathrm{~s}$ when syphilis was still treated with iodine-salts and iodine was accidentally discovered to be a contrast agent [1]. The usefulness of this radio-opacity effect is illustrated in the widespread use of iodinated contrast material: an estimated 75 million iodinated contrast injections were administered worldwide in 2005, in diagnostic/interventional procedures such as CT scans, coronary angiographies and interventions, peripheral angioplasties and stenting, etc. [2]. Assuming a continuing $9 \%$ increase a year, the number of injections will be closer to 250 million in 2020 . Fortunately contrast media are no longer extremely toxic, cell-invading salts, but have since undergone a rapid evolution to become relatively inert complex benzene molecules [3].

Despite the tremendous improvement in molecular properties, there may still be systemic and hemodynamic consequences of intravascular iodinated contrast material injection, especially for the kidneys. Over $99 \%$ of iodinated contrast material is eliminated from the body by the kidneys (possibly < $1 \%$ via liver, gallbladder, intestines, transpiration, tears, saliva) [4].

The first report of post-iodinated contrast administration acute renal failure was published in 1954 [5]. After a period of controversy, the groups at risk were recognized [6, 7]: kidney injury after iodinated contrast administration seldom occurs in patients whose kidney function is normal. Rather, acute kidney injury occurs when other insults are already present, particularly those leading to reduced perfusion of the kidneys $[8,9]$. Diabetes mellitus, advanced age, cardiovascular disease, reduction in effective intravascular volume (due to liver cirrhosis, congestive heart fail- ure or dehydration for example), and nephrotoxic medication are all compounding risk factors [10]. However, the main characteristic of high-risk patients is pre-existing renal insufficiency.

\section{Iodinated Contrast Administration and Acute Kidney Injury}

There are two main probable reasons why pre-existing renal insufficiency may predispose to acute kidney injury after contrast administration. First, diseased kidneys are less efficient with regard to excretion. Consequently, exposure to contrast after an injection is prolonged, exacerbating any toxic effects. The actual transit times will vary per individual dosage and specific contrast used. With relatively normal kidney function, contrast is probably eliminated from the body with a 2.5 hour half-life, while this half-life may be 10 hours or longer in the case of advanced renal insufficiency $[11,12]$. Second, diseased kidneys by definition already have fewer functioning nephrons, possibly chronic ischemic areas, and diminished renal adaptation mechanisms. Chronically injured kidneys therefore do not have the renal reserve to preserve glomerular filtration rate (GFR) in the event of contrast-induced injury.

Although much research has been done to elucidate the physiological pathway through which iodinated contrast materials may cause acute kidney injury, it remains unclear. Two main plausible effects through which contrast may cause kidney injury have been proposed: the first centers on the hemodynamic effects of iodinated contrast materials, alterations in blood flow and/or viscosity, which may cause reduced blood flow through the kidneys and renal ischemia; the second proposed effect is contrast toxicity to 
cells [13]. Most information on the effects of contrast on cells and organs comes from in vitro and animal studies. Toxic effects may be overestimated due to confounding variables such as contrast dilution and mixing with blood before reaching the kidney; animals with normal renal function seem to tolerate extremely high iodinated contrast material volumes without any effect on renal function [14]. A recent promising study combining an in vitro, mice model and clinical data suggests a multi-step mechanism in which activation of the immune system resident in the kidney plays an important role [15]. However, the association between intravascular iodinated contrast administration and acute kidney injury is still primarily a temporal one.

\section{From Contrast-Induced Nephropathy to Post- Contrast Acute Serum Creatinine Increase}

Serum creatinine is used to estimate GFR in clinical practice [16]. There is continual production of creatinine as a by-product of muscle metabolism, and continual excretion of it in the urine. Because the total body content of muscle creatine is fairly constant, serum creatinine levels largely depend on the rate of clearance through the kidneys.

An acute increase in serum creatinine is taken as an indication of acute kidney injury, and this is the basis for the definition of contrast-induced acute kidney injury, primarily a biochemical diagnosis. Historically the term used for this phenomenon is contrast-induced nephropathy (CIN), defined as an increase in serum creatinine $>25 \%$ or $>44 \mu \mathrm{mol} / \mathrm{l}$ from baseline within a few days after contrast exposure. It is the definition still most widely found in the literature. However, over the last years there has been some debate as to the meaning, terminology, and optimal definition for the phenomenon [17-19].

Currently most agree that there is no reason why the definition for acute kidney injury occurring after contrast exposure should differ from that of acute kidney injury in general. The current consensus therefore is to use the criteria established in the 2012 Kidney Disease Improving Global Outcome (KDIGO) guidelines [20]: a serum creatinine increase from baseline $\geq 26.5 \mu \mathrm{mol} / \mathrm{L}$ within $48 \mathrm{~h}$, or a factor of $\geq 1.5$ within the previous 7 days, or urine output reduced to $<0.5 \mathrm{~mL} / \mathrm{kg} / \mathrm{h}$ during 6 hours [18, 19, 21]. In clinical practice, especially in the outpatient setting, the more feasible serum creatinine criteria are most often used.

Part of the definition, which is often overlooked, is that the acute rise in serum creatinine is diagnosed as contrast-induced acute kidney injury only if occurring "in absence of another etiology". However, in practice it is hard to discern the correct etiology. Indeed, serum creatinine is a sensitive but non-specific surrogate indicator of renal function.

Despite its limitations and extensive research into alternate markers, serum creatinine remains the main indicator of (changes in) renal function used in clinical practice. When used as the basis for the estimation of GFR, formulas are used to correct for age, sex, and race [16]. However, serum creatinine is influenced by muscle mass, diet, hydration, and activity; it shows diurnal and seasonal fluctuations; and it is often unstable in patients with health issues [22-24]. Furthermore, sustained vasoconstriction (hours to days) observed after contrast administration [13] may be sufficient to temporarily reduce the filtration rate in the absence of acute kidney injury.

Because of the many confounding factors and uncertainties, the true implications of the often-transient post-contrast rise in serum creatinine are unclear. On the one hand, iodinated contrast injections have consistently been associated with an acute rise in serum creatinine indicating acute kidney injury $[5-7,9,10,12$, $17,18,25]$. Furthermore, although serum creatinine usually returns to baseline values within one to two weeks, it may progress to continued deterioration of renal function, a requirement of dialysis, and mortality [25], and several studies have shown correlations between post-contrast rise in serum creatinine and increased morbidity and mortality risk $[10,11,25]$. On the other hand, several retrospective studies have shown that serum creatinine fluctuations equal to those indicating contrast-induced acute kidney injury are seen without contrast administration, in incidences equal to or greater than reported incidences after contrast [26-30]. It may be that measuring post-contrast change in serum creatinine yields mostly noise, with only a few instances of acute kidney injury. However, given the persistent reports and correlations, an acute increase in serum creatinine, at the very least, is a marker and predictor of poor outcome.

Recent changes in terminology reflect the growing uncertainties surrounding the phenomenon. Until about 5 years ago, CIN was the term most widely used in the literature to refer to acute kidney injury after iodinated contrast administration ( $\triangleright$ Fig. 1). More recently it was argued that the term CIN is misleading: "Contrast-Induced" implies a causal link which has not been established in the clinical setting, mostly because studies on incidences of acute kidney injury after iodinated contrast administration lack a control group. "Contrast-Associated Nephropathy" (CAN) has been used by some instead. However, it was also argued that "Nephropathy" indicates a disease or damage to the kidney, whereas the context of intravascular iodinated contrast administration implies acute renal insult, leading to the use of the term Contrast-Induced Acute Kidney Injury (CI-AKI). Recently terms addressing both the temporal link with contrast administration and the acute nature of the phenomenon have been introduced: Contrast-Associated Acute Kidney Injury (CA-AKI), and the term recommended in current clinical practice guidelines, Post-Contrast Acute Kidney Injury (PC-AKI) ( Fig. 1) [18, 19].

In practice, there is no certainty that an acute post-contrast increase in serum creatinine greater than a predefined threshold equals acute kidney injury. In other words, post-contrast acute increase in serum creatinine (PC-ASCI) may include but does not equal contrast-induced AKI.

In the rest of this paper two terms will be used: in deference to the recommendation in updated guidelines, PC-AKI will be used to denote acute injury to the kidneys occurring after iodinated contrast material, and PC-ASCI to denote a post-contrast acute rise in serum creatinine, $>25 \%$ or $>44 \mu \mathrm{mol} / \mathrm{l}$ from baseline, as measured in clinical practice and most trials to date. 


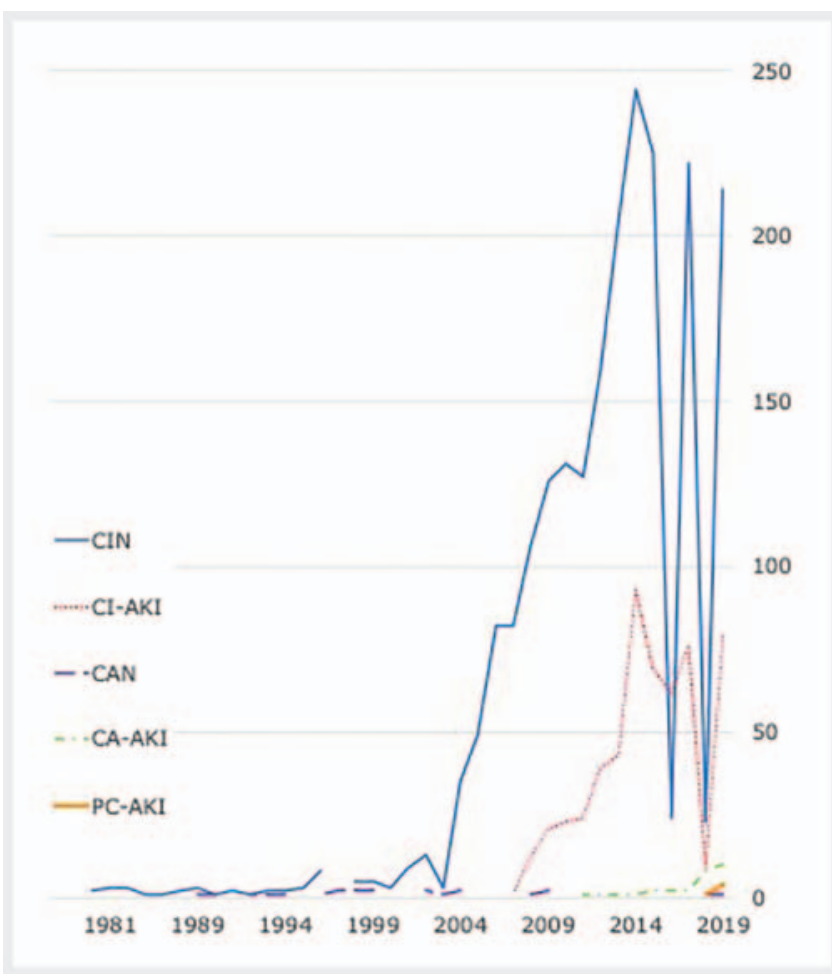

- Fig. 1 Number of publications using the terms CIN, CI-AKI, CAN, CA-AKI, or PC-AKI to denote an increase in serum creatinine after iodinated contrast administration (PubMed search done on February $4^{\text {th }}, 2020$ ).

- Abb. 1 Anzahl der Publikationen mit den Suchbegriffen CIN, CI-AKI, CAN, CA-AKI oder PC-AKI mit Erwähnung eines Anstiegs des Serumkreatinins nach Gabe jodhaltiger Kontrastmittel (PubMed-Suche am 4. Februar 2020).

\section{Guidelines for the Prevention of Post-Contrast Acute Kidney Injury}

Once acute kidney injury has occurred, no known treatment is available to mitigate possible effects. As a consequence, the focus in clinical practice is on prevention. The identification of high-risk patients around the $1980 \mathrm{~s}$ enabled a more structured approach and standardization of preventive measures, and several radiological committees were formed in the $1990 \mathrm{~s}$ to that end. Around the year 2000, national and umbrella radiologic societies began issuing guidelines on the safe use of intravascular iodinated contrast material. Examples of umbrella organizations are ESUR for Europe, ACR for the United States of America, and RANZCR for New Zealand and Australia [31-33]. Many countries have their own guidelines, such as the United Kingdom [34] and the Netherlands [18]. Germany does not have a national guideline for the prevention of PC-AKI, and it is assumed the European ESUR guideline is followed.

Clinical practice guidelines are defined as "systematically developed statements to assist practitioner and patient decisions about appropriate health care for specific clinical circumstances" (The Institute of Medicine). They include concise instructions on patient selection, diagnostic/screening tests, medical/surgical procedures, and other clinical practice details. They are regularly updated, incorporating systematic literature reviews, and thus reflect current evidence-based knowledge in the field.

Guidelines for the prevention of PC-AKI specify how to identify at-risk patients and how best to prevent PC-AKI in these patients $[18,31-34]$. Patients at risk of PC-AKI have specific risk factors, mainly pre-existing renal insufficiency or, in other words, patients with chronic kidney disease (CKD). Procedure-related risk factors are contrast type (e.g. dimer > monomer; high > low osmolality) and volume (iodine dose); administration route (first pass renal exposure > intra-arterial > intravenous); and repeated contrast injections. To reduce procedure-related risks, optimal contrast administration is stressed, such as using a contrast volume that is as low as feasible. Aiming for clinical euvolemia and withholding medication such as metformin, NSAIDs, and ACE inhibitors in high-risk patients are recommended to reduce patient-related risk factors.

Guidelines agree that no medicinal prophylaxes studied to date (e. g. statins, NAC) have been shown to consistently protect against PC-AKI. The prophylaxis universally recommended to prevent PC-AKI is intravenous hydration.

\section{To Hydrate or Not To Hydrate? Intravenous Prophylactic Hydration}

Intravenous hydration as prophylaxis for PC-AKI was first introduced in the literature in 1981 [35]. Since then peri-procedural intravenous hydration has been strongly recommended, and it is still the cornerstone treatment for PC-AKI prevention today.

The pathophysiological pathway through which intravenous hydration protects renal function is unclear, mainly because the physiological pathway of PC-AKI is unclear. However, there is consensus among experts that administering intravenous fluids before and after contrast exposure may mitigate some of the hemodynamic effects of contrast material by reducing blood osmolality and viscosity. It has been shown that contrast is rapidly filtered and excreted in the urine of euvolemic mice, whereas it is reabsorbed and accumulates in the tubules during volume depletion [15]. The main mechanism by which intravenous hydration is thought to work is by producing an infusion rate-dependent increase in tubular fluid volume [36].

Water infusion alone could reduce intra-tubular contrast concentration. In recommended prophylaxis protocols, sodium chloride or sodium bicarbonate is added. Sodium chloride may induce a tubular reaction to increase salt and water excretion, which may theoretically promote contrast excretion. Furthermore, increased salt excretion may cause a slight reduction in tubular acidity. The acid handled by a kidney is relatively constant over limited periods of time, therefore increasing volume in the tubuli through infusion will reduce acid concentration. Apoptosis (programmed cell death) after free radical generation has been shown to be accelerated in an acid environment in vitro: by increasing tubular $\mathrm{pH}$, physiological sodium chloride solution may attenuate free radical-induced damage. Intravenous hydration with $1.4 \%$ sodium bicarbonate theoretically has all the same beneficial influences as normal saline, with the added potential benefits of substantial renal tubule alkalinization and free radical clearing [36]. 
For the prevention of PC-AKI, intravenous hydration with normal saline is considered the absolute gold standard. However, evidence for effectiveness is scarce $[25,37]$. It has not been conclusively shown that this prophylaxis mitigates PC-AKI risk, let alone whether it reduces the risks of dialysis and mortality in the long term. Clinical trials evaluating strategies to prevent PC-AKI mostly focus on a comparison of two or more variations of intravenous prophylaxis and lack a control group not receiving any prophylaxis. Only relatively recently were trials incorporating such a control group published.

Two trials, published in 2014 and 2015, included patients with normal GFR and CKD patients and evaluated intravenous hydration with normal saline versus no prophylaxis [38, 39]. Two found lower PC-ASCl incidences after prophylaxis (22/108 vs. 38/108 [38] and $22 / 204$ vs. $43 / 204$ [39]). Less in-hospital mortality for the prophylaxis group was reported in one trial (3/108 vs. 10/108) [38], but no difference between groups was reported in the other [39]. However, both trials were set in acute care (primary percutaneous intervention for ST-elevation myocardial infarction), where hemodynamic instability and other factors play a role.

Several trials were done in computed tomography (CT) comparing 1 -hour $1.4 \%$ sodium bicarbonate intravenous hydration before contrast administration to no prophylaxis. Among the included normal and CKD patients, no difference in efficacy was found (PC-ASCI 3/43 vs. 4/44) [40]. The sample size was very small, however, and the included patients with estimated GFR $(e G F R) \geq 60 \mathrm{~mL} / \mathrm{min} / 1.73 \mathrm{~m}^{2}$ are not considered at risk. A second small trial was done in patients suspected of pulmonary embolism; all patients had CKD. No prophylaxis was found non-inferior (PC-ASCI 5/70 vs. 6/65) [41]. This year a similar but larger study was published: the multi-center KOMPAS study included all CKD outpatients undergoing elective contrast-enhanced CT. Again, no prophylaxis was found non-inferior (PC-ASCI 7/262 vs. 4/261, no instances of dialysis and similar incidences of mortality at one-year follow-up) [42]. These three trials appear to indicate no benefit of prophylactic intravenous hydration in the elective setting of computed tomography. However, hydration protocols in these studies deviate from traditionally recommended protocols. First, sodium bicarbonate was used instead of the more widely accepted normal saline, but this may not be a major issue since no notable differences between pre- and post-contrast prophylaxis with sodium chloride and sodium bicarbonate have been reported in the literature [e.g. 43]. Second, considering the plausible mechanisms of PC-AKI, the preventive effect of intravenous fluids is probably rate-dependent [36]. In other words, in order to be fully effective, intravenous hydration must probably be continued for the time it takes the kidneys to filter out the contrast material. The possibility that 1-hour pre-hydration is simply not enough to make a difference therefore cannot be excluded. It must also be noted that several retrospective studies question the risk of intravenous contrast administration [e. g. 44].

The only trial to date comparing intravenous prophylactic preand post-hydration with normal saline in elective CKD patients receiving intravenous or intraarterial iodinated contrast is the AMACING trial $[45,46]$. All referrals for elective procedures with iodinated contrast were included in screening for patients that were at risk according to current at the time of the trial Dutch and European guidelines. Non-inferiority of no prophylaxis to standard prophylaxis in the prevention of PC-AKI was shown: PC-ASCI 8/296 (2.7\%) vs. 8/307 (2.6\%); no dialysis or related deaths at one month; no clinically relevant differences in oneyear dialysis, mortality, change in serum creatinine, or renal events. In short, no benefits of prophylactic intravenous hydration could be discerned. On the other hand, prophylaxis is not without risk (complications of intravenous hydration occurred in $5.5 \%$ of hydrated patients), requires extra hospitalization of patients, and incurs considerable costs. These findings led to the conclusion that standard prophylaxis can be safely withheld for patients like those included in the AMACING trial.

\section{eGFR < $30 \mathrm{~mL} / \mathrm{min} / 1.73 \mathrm{~m}^{2}$ patients: what do we know?}

The available evidence from controlled trials for the effectiveness of prophylactic intravenous hydration is limited, and pertains to patients with eGFR $\geq 30 \mathrm{~mL} / \mathrm{min} / 1.73 \mathrm{~m}^{2}$ only. The AMACING trial, for example, included elective patients with eGFR $30-59 \mathrm{~mL} / \mathrm{min} / 1.73 \mathrm{~m}^{2}$ combined with the risk factors diabetes, cardiovascular disease, age $>75$, anemia, or nephrotoxic medication. eGFR $<30 \mathrm{~mL} / \mathrm{min} / 1.73 \mathrm{~m}^{2}$ patients (i. e., CKD stages $4 \& 5$ ) were excluded. These patients represent only a small fraction of all patients receiving intravascular iodinated contrast.

In the general population, the prevalence of stages 4 \& 5 CKD is $0.4 \%$ to $0.5 \%$. In the setting of elective intravascular iodinated contrast administration, the prevalence is even lower, $0.06 \%$ to $0.5 \%$ [47]. Consequently, very few trials manage to include even a few cases, and little is known about PC-AKI and prophylaxis in these patients. Worldwide, however, based on the prevalence and estimated number of contrast procedures, at least 375000 and up to 1.25 million patients with this severe level of CKD will be confronted with the risks of contrast administration each year $[2,47]$.

A retrospective analysis comparing the excluded eGFR $<30 \mathrm{~mL} / \mathrm{min} / 1.73 \mathrm{~m}^{2}$ patients from the AMACING trial to enrolled patients (with eGFR 30-59 mL/min/1.73 $\mathrm{m}^{2}$ ) found the former to be at significantly higher risk [47]: PC-ASCI $13.6 \%$ vs. $2.7 \%(p=0.0019)$; dialysis at 1 month $0.9 \%$ vs. $0.0 \%$ $(p=0.2646)$; and mortality at 1 month $9.2 \%$ vs. $0.0 \%$ $(p<0.0001)$.

A much larger, 4-year retrospective observational study of elective procedures in eGFR $<30 \mathrm{~mL} / \mathrm{min} / 1.73 \mathrm{~m}^{2}$ patients with intravascular iodinated contrast administration, found that prophylactic intravenous hydration might confer some benefit for renal function [48]. Results did not reach statistical significance, but point estimates indicated a protective trend compared to patients without prophylaxis (PC-ASCI, GFR decline and 1-month dialysis all yielded adjusted odds ratios $<1$ ). On the other hand, analyses of 1-month all-cause mortality yielded adjusted odds ratios $>1$, indicating a trend toward higher short-term mortality risk for prophylaxis patients. Confounding by indication may play a part in the latter observation, but prophylaxis complications contributed to the observed higher mortality risk. Amongst the 281 eGFR $<30 \mathrm{~mL} / \mathrm{min} / 1.73 \mathrm{~m}^{2}$ prophylaxis patients studied, 
- Table 1 Current recommendations in recently updated guidelines for the prevention of PC-AKI.

- Tab. 1 Heutige Empfehlungen auf Basis der jüngst revidierten Richtlinien zur Prävention einer PC-AKI.

\begin{tabular}{|c|c|c|c|c|}
\hline guideline & update & definition used & patient-related risk factors & recommended prophylactic treatment for high-risk patients \\
\hline$N V v R(N L)$ & 2017 & $\begin{array}{l}\text { KDIGO criterion } 1 \text { or } \\
2 \text { measure at } 2-7 d\end{array}$ & $\mathrm{eGFR}<30 \mathrm{~mL} / \mathrm{min} / 1.73 \mathrm{~m}^{2}$ & $\begin{array}{l}\text { iv } 1.4 \% \mathrm{NaHCO}_{3} \\
1 \mathrm{~h} \text { pre-CM at } 3 \mathrm{~mL} / \mathrm{kg} / \mathrm{h} \text { (or } 250 \mathrm{ml} \text { ) } \\
\text { or } 1 \mathrm{~h} \mathrm{pre-CM} \text { at } 3 \mathrm{~mL} / \mathrm{kg} / \mathrm{h} \text { (or } 250 \mathrm{ml} \text { ) and } 6 \mathrm{~h} \text { post-CM at } \\
1 \mathrm{~mL} / \mathrm{kg} / \mathrm{h} \text { (or } 500 \mathrm{ml} \text { ) }\end{array}$ \\
\hline ESUR (Europe) & 2018 & $\begin{array}{l}\text { KDIGO criterion } 1 \text { or } \\
2 \text { within } 48-72 h\end{array}$ & $\begin{array}{l}\text { eGFR }<30 \mathrm{~mL} / \mathrm{min} / 1.73 \mathrm{~m}^{2} \\
\text { eGFR }<45 \mathrm{~mL} / \mathrm{min} / 1.73 \mathrm{~m}^{2} \\
\text { before } 1^{\text {st }} \text { pass renal exposure } \\
\text { or in ICU patients }\end{array}$ & $\begin{array}{l}\text { iv } 0.9 \% \mathrm{NaCl} \\
3-4 \mathrm{~h} \text { pre-CM at } 1 \mathrm{~mL} / \mathrm{kg} / \mathrm{h} \text { and } 4-6 \mathrm{~h} \text { post-CM at } 1 \mathrm{~mL} / \mathrm{kg} / \mathrm{h} \\
\text { or iv } 1.4 \% \mathrm{NaHCO}_{3}(\mathrm{or} 154 \mathrm{mmol} / / \mathrm{in} \text { dextrose } 5 \% \text { water) } \\
1 \mathrm{~h} \text { pre- } \mathrm{CM} \text { at } 3 \mathrm{~mL} / \mathrm{kg} / \mathrm{h} \text {; for } 1^{\text {st }} \text { pass renal exposure also } 4-6 \mathrm{~h} \\
\text { post- } \mathrm{CM} \text { at } 1 \mathrm{~mL} / \mathrm{kg} / \mathrm{h} \\
\text { - The clinician responsible for patient care should individualize } \\
\text { preventive hydration in patients with severe congestive heart failure } \\
\text { or patients with end-stage renal failure }\end{array}$ \\
\hline $\begin{array}{l}\text { RANZCR } \\
\text { (Oceania) }\end{array}$ & 2018 & $\begin{array}{l}\text { None - refer to NICE } \\
\text { guideline } \\
\text { within } 48 \mathrm{~h} \text { or } 7 d\end{array}$ & $\begin{array}{l}\text { eGFR }<30 \mathrm{~mL} / \mathrm{min} / 1.73 \mathrm{~m}^{2} \\
\mathrm{e} G F R<45 \mathrm{~mL} / \mathrm{min} / 1.73 \mathrm{~m}^{2} \text { in } \\
\text { deteriorating renal function }\end{array}$ & $\begin{array}{l}\text { iv } 0.9 \% \mathrm{NaCl} \\
\text { "There is no evidence to support a specific volume or duration... } \\
\text { A practical protocol ... is } 1.0-1.5 \mathrm{~mL} / \mathrm{kg} / \mathrm{h} \text {, for at least } 6 \mathrm{~h} \text { before } \\
\text { and after ..." } \\
\text { - Exact administration protocols depend on, amongst other things, } \\
\text { the patient's pre-test risk of cardiac failure/pulmonary oedema }\end{array}$ \\
\hline ACR (America) & 2020 & $\begin{array}{l}\text { AKIN criteria } \\
\text { within } 48 \mathrm{~h}\end{array}$ & eGFR $<30 \mathrm{~mL} / \mathrm{min} / 1.73 \mathrm{~m}^{2}$ & $\begin{array}{l}\text { iv } \mathbf{0 . 9} \% \mathrm{NaCl} \text { (or Lactated Ringer's) } \\
\text { "The ideal infusion rate and volume is unknown... One possible } \\
\text { protocol would be ... } 100 \mathrm{~mL} / \mathrm{h} \text {, beginning } 6 \text { to } 12 \mathrm{~h} \text { before and } \\
\text { continuing } 4 \text { to } 12 \mathrm{~h} \text { after..." }\end{array}$ \\
\hline $\begin{array}{l}\text { NKF-ACR } \\
\text { statement } \\
\text { (America) }\end{array}$ & 2020 & $\begin{array}{l}\text { KDIGO criteria } \\
\text { within } 48 \mathrm{~h}\end{array}$ & $\begin{array}{l}\text { eGFR }<30 \mathrm{~mL} / \mathrm{min} / 1.73 \mathrm{~m}^{2} \\
\text { eGFR }<45 \mathrm{~mL} / \mathrm{min} / 1.73 \mathrm{~m}^{2} \text { in } \\
\text { "individual high-risk circum- } \\
\text { stances" }\end{array}$ & $\begin{array}{l}\text { iv } \mathbf{0 . 9} \% \mathrm{NaCl} \text { ("iv } 1.4 \% \mathrm{NaHCO}_{3} \text { is not preferred") } \\
\text { "The ideal timing, volume, and rate of volume expansion is } \\
\text { uncertain. Typical ... regimens begin } 1 \mathrm{~h} \text { before and continue 3- } \\
12 \mathrm{~h} \text { after ... with typical doses ranging from fixed (e. g., } 500 \mathrm{~mL} \\
\text { before and after) to weight-based volumes }(1-3 \mathrm{~mL} / \mathrm{kg} / \mathrm{h} \text { )" } \\
\text { - Risk of prophylaxis should be considered before initiation }\end{array}$ \\
\hline \multicolumn{5}{|c|}{ 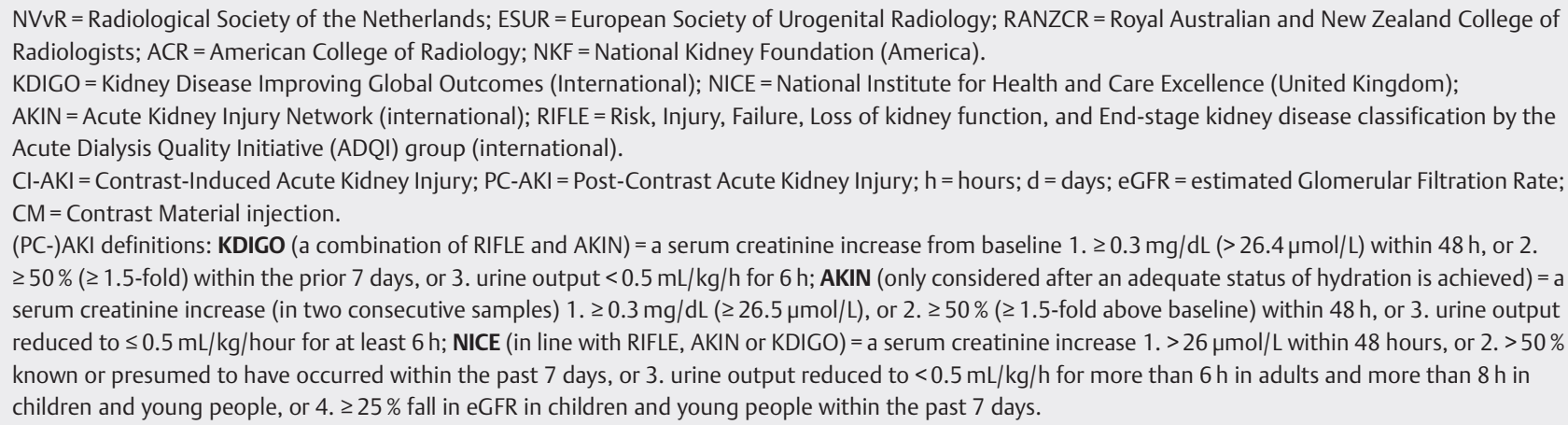 } \\
\hline
\end{tabular}

18 (6.4\%) serious complications occurred: 3 arrhythmias, and 15 heart failures. The latter included 5 deaths. Of all deaths observed in prophylaxis patients, $24 \%$ (5/21) were adjudicated as related to intravenous prophylactic hydration.

The study incorporated a comparison of baseline characteristics between patients who had suffered serious complications and those who had not. The results suggested that evaluating individual cardiac function parameters before prescribing prophylaxis for high-risk patients with eGFR $<30 \mathrm{~mL} / \mathrm{min} / 1.73 \mathrm{~m}^{2}$ may help to identify those prone to serious complications [48].

\section{Recommendations for Current Clinical Practice}

PC-AKI prevention guidelines have drastically changed in recent years. Optimal contrast administration, adhering to the ALARA (As Low As Reasonably Achievable) principle, remains perhaps the most important prerequisite for patient safety. On the subject of PC-AKI and prophylaxis, however, many questions remain unanswered and evidence is still lacking. There is no evidence, for example, for an optimal prophylactic protocol. At this time pre- and post-contrast intravenous hydration with normal saline seems to be the preferred protocol ( $\vee$ Table 1$)$. 


\section{RISK SCREENING AND PREVENTIVE MEASURES FOR ELECTIVE PROCEDURES WITH INTRAVASCULAR IODINATED CONTRAST ADMINISTRATION \\ in acute settings the treating physician must determine which preventive measures are to be taken}

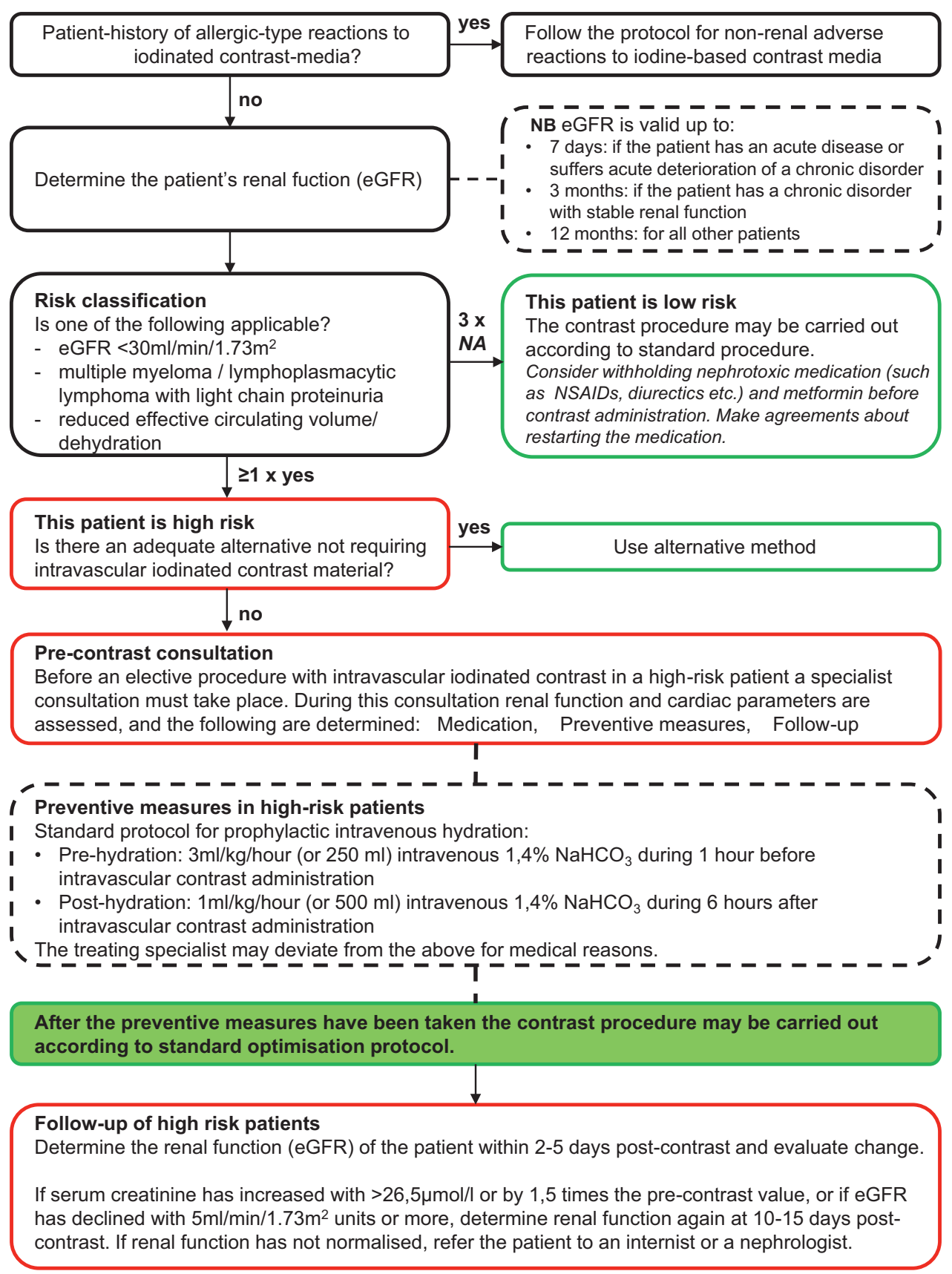

Fig. 2 Clinical practice flowchart for the prevention of PC-AKI (according to our internal Maastricht UMC+ standard operating procedure).

- Abb. 2 Klinisches Screening-Diagramm zur Vermeidung einer PC-AKI (standardisierte interne Vorgehensweise (Maastricht UMC+)).

Aiming for a euvolemic state in all patients before a procedure is an integral part of optimal contrast administration. Dehydrated patients are at higher risk of acute kidney injury and should therefore be re-hydrated before contrast administration irrespective of renal function. However, standard prophylactic intravenous hydra- tion is no longer recommended in eGFR $\geq 30 \mathrm{~mL} / \mathrm{min} / 1.73 \mathrm{~m}^{2} \mathrm{pa}$ tients. Elective patients with eGFR $30-59 \mathrm{~mL} / \mathrm{min} / 1.73 \mathrm{~m}^{2}$ combined with the risk factors diabetes, anemia, cardiovascular disease, or nephrotoxic medication have been relegated from the 'high-risk' to the 'low to intermediate-risk' group, and the stand- 
ard prophylaxis threshold is now set at eGFR $<30 \mathrm{~mL} / \mathrm{min} / 1.73 \mathrm{~m}^{2}$ ( $\vee$ Table 1). This does indeed appear to better define the high-risk population [47-49].

This change in recommendations has already had an enormous beneficial impact on current clinical practice of guideline-adhering medical centers, enormously reducing complications, hospitalizations, and costs [50]. Another welcome change is that most guidelines now specifically mention the risk of intravenous hydration. This previously unrecognized but important aspect of safe iodinated contrast material administration is especially relevant for eGFR $<30 \mathrm{~mL} / \mathrm{min} / 1.73 \mathrm{~m}^{2}$ patients [49]. An appropriate dual screening process, including both renal and cardiac parameters (see example in > Fig. 2), will minimize the risk of prophylactic hydration in this high-risk population.

\section{Conflict of Interest}

\section{Wildberger JE}

Institutional grants: AGFA, Bayer Healthcare, Bard Medical, GE Healthcare, Optimed, Philips Healthcare, Siemens Healthineers.

Speaker's bureau: Siemens Healthineers, Bayer Healthcare.

Other authors: NONE

Research funded by Stichting de weijerhorst.

\section{References}

[1] Osborne ED, Sutherland CG, Scholl AJ et al. Roentgenography of urinary tract during excretion of sodium iodide. JAMA 1923; 80: 368-373

[2] Christiansen C. X-ray contrast media: an overview. Toxicology 2005; 209 : 185-187

[3] Buschur M, Aspelin P. Contrast media: history and chemical properties Interv Cardiol Cli 2014; 3: 333-339

[4] Svaland MG, Haider T, Langseth-Manrique K et al. Human pharmacokinetics of iodixanol. Invest Radiol 1992; 27: 130-133

[5] Bartels ED, Brun GC, Gammeltoft A et al. Acute anuria following intravenous pyelography in a patient with myelomatosis. Acta Med Scand 1954; 150: 297-302

[6] Harkonen S, Kjellstrand C. Contrast nephropathy. Am J Nephrol 1981; 1: 69-77

[7] Berkseth RO, Kjellstrand CM. Radiologic contrast-induced nephropathy. Med Clin N Am 1984; 68: 351-370

[8] Heyman SN, Rosen S, Brezis M. Radiocontrast nephropathy: a paradigm for the synergism between toxic and hypoxic insults in the kidney. Exp Nephrol 1994; 2: 153-157

[9] Morcos SK, Epstein FH, Haylor J et al. Aspects of contrast media nephrotoxicity. Eur J Radiol 1996; 23: 174-184

[10] Mehran R, Nikolsky E. Contrast-induced nephropathy: definition, epidemiology, and patients at risk. Kidney Int 2006; 69: S111-S115

[11] Nossen JO, Jakobsen JA, Kjaersgaard P et al. Elimination of the non-ionic $\mathrm{X}$-ray contrast media iodixanol and iohexol in patients with severely impaired renal function. Scand J Clin Lab Invest 1995; 55: 341-350

[12] Usutani S. Contrast nephropathy with a non-ionic iodide medium in patients with normal and mildly impaired renal function. Jap J Nephrol 2000; 42: 338-345

[13] Fähling M, Seeliger E, Patzak A et al. Understanding and preventing contrast-induced acute kidney injury. Nature Reviews Nephrol 2017; 13 : $169-180$

[14] Krause W. In vitro and animal experiments in contrast media testing. Invest Radiol 1998; 33: 182-191
[15] Lau A, Chung H, Komada T et al. Renal immune surveillance and dipeptidase-1 contribute to contrast-induced acute kidney injury. J Clin Invest 2018; 128: 2894-2913

[16] Chronic Kidney Disease Epidemiology Collaboration. Using standardized serum creatinine values in the Modification of Diet in Renal Disease study equation for estimating glomerular filtration rate. Ann Intern Med 2006; 145: 247-254

[17] Budano C, Levis M, D’Amico M et al. Impact of contrast-induced acute kidney injury definition on clinical outcomes. Am Heart J 2011; 161: 963-971

[18] Nederlandse Vereniging voor Radiologie. Guideline Safe Use of Contrast Media. Available via (accessed 28 Feb 2020): https://www.radiologen.nl/ kwaliteit/richtlijnen-veilig-gebruik-van-contrastmiddelen-guidelinessafe-use-contrast-media

[19] Van der Molen AJ, Reimer P, Dekkers IA et al. Post-contrast acute kidney injury- Part 1: definition, clinical features, incidence, role of contrast medium and risk factors: Recommendations for updated ESUR Contrast Medium Safety Committee guidelines. Eur Radiol 2018; 28: 2845-2855

[20] Kidney Disease: Improving Global Outcomes (KDIGO) Acute Kidney Injury Work Group. KDIGO clinical practice guideline for acute kidney injury. Kidney Int Suppl 2012; 2: 1-138

[21] Davenport MS, Perazella MA, Yee J et al. Use of Intravenous lodinated Contrast Media in Patients with Kidney Disease: Consensus Statements from the American College of Radiology and the National Kidney Foundation. Radiology 2020; 00: 1-9

[22] Bargnoux AS, Kuster N, Cavalier E et al. Serum creatinine: advantages and pitfalls. J Lab Pres Med 2018; 3: 71

[23] Pocock S], Ashby D, Shaper AG et al. Diurnal variations in serum biochemical and haematological measurements. J Clin Pathol 1989; 42: $172-179$

[24] Ranucci M, Castelvecchio S, La Rovere MT et al. Renal function changes and seasonal temperature in patients undergoing cardiac surgery. Chronobiol Int 2014; 31: 175-181

[25] James MT, Samuel SM, Manning MA et al. Contrast-induced acute kidney injury and risk of adverse clinical outcomes after coronary angiography: a systematic review and meta-analysis. Circ Cardiovasc Interv 2013; 6: $37-43$

[26] Rifkin DE, Coca SG, Kalantar-Zadeh K. Does AKI really lead to CKD? J Am Soc Nephrol 2012; 23: 979-984

[27] Newhouse JH, Kho D, Rao QA et al. Frequency of serum creatinine changes in the absence of iodinated contrast material: implications for studies of contrast nephrotoxicity. Am J Roentgenol 2008; 191: 376-382

[28] Bruce R], Djamali A, Shinki K et al. Background fluctuation of kidney function versus contrast-induced nephrotoxicity. Am J Roentgenol 2009; 192: 711-718

[29] McDonald JS, McDonald RJ, Comin J et al. Frequency of acute kidney injury following intravenous contrast medium administration: a systematic review and meta-analysis. Radiology 2013; 267: 119-128

[30] McDonald RJ, McDonald JS, Bida JP et al. Intravenous contrast materialinduced nephropathy: causal or coincident phenomenon? Radiology 2013; 267: 106-118

[31] European Society of Urogenital Radiology. ESUR guidelines on contrast media. Available via http://www.esur.org/guidelines/ (old version) \& http://www.esur.org/esur-guidelines/ (newest versions); accessed 28 Feb 2020

[32] Committee on Drugs and Contrast Media, American College of Radiology (ACR). Manual on contrast media. Available via (accessed 28 Feb 2020): http://www.acr.org/quality-safety/resources/contrast-manual

[33] The Royal Australian and New Zealand College of Radiologists. RANZCR iodinated contrast guidelines. Available via (accessed 28 Feb 2020): https://www.ranzcr.com/fellows/clinical-radiology/professionaldocuments/ranzcr-iodinated-contrast-guidelines 
[34] The National Institute for Health and Care Excellence (2017) Surveillance report (exceptional review) 2017 - Acute kidney injury: prevention, detection and management 2013 NICE guideline CG169. Available via (accessed 28 Feb 2020): https://www.nice.org.uk/guidance/ng148/ evidence/a-preventing-contrastinduced-acute-kidney-injurypdf-7019265566

[35] Eisenberg RL, Bank WO, Hedgock MW. Renal failure after major angiography can be avoided with hydration. Am J Radiol 1981; 136: 859-861

[36] Burgess WP, Walker PJ. Mechanisms of contrast-induced nephropathy reduction for saline $(\mathrm{NaCl})$ and sodium bicarbonate (NaHCO3). Biomed Res Inz 2014; 2014: 510385

[37] Van der Molen AJ, Reimer P, Dekkers IA et al. Post-contrast acute kidney injury. Recommendations for updated ESUR Contrast Medium Safety Committee guidelines. Part 2: risk stratification, role of hydration and other prophylactic measures, patients taking metformin and chronic dialysis patients. Eur Radiol 2018; 28: 2856-2869

[38] Luo Y, Wang X, Ye Z et al. Remedial hydration reduces the incidence of contrast- induced nephropathy and short-term adverse events in patients with ST-segment elevation myocardial infarction: a single-center, randomized trial. Intern Med 2014; 53: 2265-2272

[39] Jurado-Roman A, Hernández-Hernández F, García-Tejada J et al. Role of hydration in contrast-induced nephropathy in patients who underwent primary percutaneous coronary intervention. Am J Cardiol 2015; 115: $1174-1178$

[40] Martin-Moreno PL, Varo N, Martinez-Anso E et al. Comparison of intravenous and oral hydration in the prevention of contrast-induced acute kidney injury in low- risk patients: a randomized trial. Nephron 2015; 131: $51-58$

[41] Kooiman J, Sijpkens YW, van Buren M et al. Randomised trial of no hydration vs. sodium bicarbonate hydration in patients with chronic kidney disease undergoing acute computed tomography-pulmonary angiography. J Thromb Haemost 2014; 12: 1658-1666
[42] Timal RJ, Kooiman J, Sijpkens YW et al. No prehydration versus sodium bicarbonate prehydration prior to contrast-enhanced $C T$ in the prevention of post-contrast acute kidney injury: The Kompas Randomized Clinical Trial. JAMA Intern Med 2020; 180: 533-541

[43] Weisbord SD, Gallagher M, Jneid H et al. Outcomes after angiography with sodium bicarbonate and acetylcysteine. N Engl J Med 2018; 378 : 603-614

[44] McDonald JS, McDonald RJ, Lieske JC et al. Risk of acute kidney injury, dialysis, and mortality in patients with chronic kidney disease after intravenous contrast material exposure. Mayo Clin Proc 2015; 90: 10461053

[45] Nijssen EC, Rennenberg RJ, Nelemans PJ et al. Prophylactic hydration to protect renal function from intravascular iodinated contrast material in patients at high-risk of contrast-induced acute kidney injury (AMACING): a prospective, randomised, phase 3, controlled, open-label, non-inferiority trial. Lancet 2017; 389: 1312-1322

[46] Nijssen EC, Nelemans PJ, Rennenberg RJ et al. Prophylactic intravenous hydration to protect renal function from intravascular iodinated contrast material (AMACING): long-term results of a prospective, randomised, controlled trial. E Clinical Medicine by the Lancet 2018; 4-5: 109-116

[47] Nijssen EC, Nelemans PJ, Rennenberg RJ et al. Evaluation of safety guidelines on the use of iodinated contrast material: conundrum continued. Invest Radiol 2018; 53: 616-622

[48] Nijssen EC, Nelemans PJ, Rennenberg RJ et al. Prophylaxis in high-risk patients with eGFR $<30 \mathrm{ml} / \mathrm{min} / 1.73 \mathrm{~m}^{2}$ : get the balance right. Invest Radiol 2019; 54: 580-588

[49] Gorelik Y, Bloch-Isenberg N, Yaseen H et al. Acute kidney injury after radiocontrast-enhanced computerized tomography in hospitalized patients with advanced renal failure: a propensity-score-matching analysis. Invest Radiol 2020; 55: 677-687

[50] Nijssen EC, Nelemans PJ, Rennenberg RJ et al. Impact on clinical practice of updated guidelines on iodinated contrast material: CINART. Eur Radiol 2020; 30: 4005-4013 